\title{
Psychological Aspects in Continuous Subcutaneous Insulin Infusion: A Retrospective Study
}

\author{
INGO ABERLE \\ Technische Universität Dresden \\ URTE SCHOLZ \\ University of Zurich \\ BIRGIT BACH-KLIEGEL \\ Hirslanden Clinic \\ CHRISTINE FISCHER \\ Schwäebisch Hall \\ MARTIN GORNY \\ KARIN LANGER \\ City Hospital Darmstadt \\ MATTHIAS KLIEGEL \\ Technische Universität Dresden
}

\begin{abstract}
The authors aimed to analyze the relation of psychological predictors with medical and psychological therapy success indicators in continuous subcutaneous insulin infusion (CSII). Besides blood glucose control as a medical indicator of therapy success (by means of $\mathrm{HbA}_{1 \mathrm{c}}$ levels), the authors assessed treatment satisfaction, depressive symptoms, and quality of life among 51 adult patients on CSII. The authors examined the following psychological factors that were assumed to be associated with outcome variables: coping style, locus of control, and self-efficacy. Self-efficacy correlated positively with all psychological outcome variables. A high external locus of control was related to negative glycaemic outcome and more depressive symptoms. Multiple linear regression analyses revealed that when considering all psychological factors simultaneously, locus of control was the strongest predictor of $\mathrm{HbA}_{1 \mathrm{c}}$. For the psychological outcomes, self-efficacy was the most powerful predictor. The authors demonstrated that medical and psychological diabetes-related outcomes were strongly related to psychological factors in adult CSII patients. Patients who felt responsible for the process of CSII therapy showed more positive outcomes; therefore, psychological care can be seen as an important part of diabetes education in CSII therapy.
\end{abstract}

Keywords: depression, locus of control, quality of life, self-efficacy, type 1 diabetes 
AS THE SIXTH LEADING CAUSE OF DEATH, diabetes is one of the most significant chronic illnesses affecting the general population (Arias, Anderson, Kung, Murphy, \& Kochanek, 2003; Centers for Disease Control and Prevention, 2004). Patients are at increased risk of death because of the causes of diabetes and diabetes-related pathological processes (Geiss, Herman, \& Smith, 1995; McEwen et al., 2006). Diabetes-management factors controlled by the patient, such as monitoring glycemic control and adherence to diet, are essential daily components of effective diabetes management (American Diabetes Association, 2005). Hence, psychological constructs (e.g., self-efficacy, depression) have been identified as affecting development and progression of diabetes (Sacco, Wells, \& Vaughan, 2005; Talbot \& Nouwen, 2000). Therefore, interdisciplinary diabetes education conveying medical and psychological guidelines is crucial for a tight diabetic management system (Adili, Larijani, \& Haghighatpanah, 2006; DeVries, Snoek, \& Heine, 2004).

Although an increasing body of literature has emerged on psychosocial factors involved in conventional diabetes therapy, one more recent therapy option has received much less attention from a psychological perspective: continuous subcutaneous insulin infusion (CSII). In the present study, a small, portable, external pump applied short-acting insulin in constant small portions to diabetic patients to mimic nondiabetic insulin delivery. Effective metabolic control should be attainable if therapy is conducted appropriately. Several findings point in this direction (e.g., Aberle et al., 2008). Important for the present study is that CSII therapy requires particularly active involvement of the patient (e.g., regular blood glucose self-monitoring); thus, researchers have described psychological aspects of health behavior to be of special interest and essential for therapy success (Pickup \& Keen, 2002). Surprisingly, however, although the advantages of CSII in medical outcomes are apparent (Pickup, Mattock, \& Kerry, 2002), "the amount of literature on psychosocial outcomes is considerably less than the amount of literature on metabolic outcomes" (Weissberg-Benchell, Antisdel-Lomaglio, \& Seshadri, 2003, p. 1079).

In addition, psychosocial variables may be relevant as not only outcomes but also predictors of metabolic control. Only a few studies on this topic are available on treatment of adults with CSII (Chlebowy \& Garvin, 2006; Diem, Frost, Augustiny, \& Radanov, 2004; Graue, Wentzel-Larsen, Bru, Hanestad, \& Søvik, 2004; Johnston-Brooks, Lewis, \& Garg, 2002; Nakahara et al., 2006). In these reports, the authors discussed coping, locus of control, or self-efficacy as being an important factor for therapy success.

We followed up on these initial reports and, for the first time, tested the effect of a battery of psychosocial predictors on medical and several psychological outcome parameters. In doing so, we targeted both basic and applied research

Address correspondence to Matthias Kliegel, Technische Universität Dresden, Department of Psychology, D-01062, Dresden, Germany; kliegel@psychologie.tu-dresden.de $(e-$ mail $)$. 
aims. Specifically, we aimed to further explore the role of key psychological constructs (e.g., self-efficacy) in managing chronic diseases (e.g., diabetes) and to identify important psychosocial parameters that should be considered in interdisciplinary disease management and patient education.

Of possible psychosocial predictors, we assessed coping, locus of control, and self-efficacy. Regarding coping, we applied Krohne's (1993) model. In the present study, we distinguished two strategies in dealing with threatening situations: vigilance and cognitive avoidance. A vigilant strategy reflects being oriented toward the threat-related aspects of a situation. A cognitive avoidant strategy implies turning attention away from threatening cues. We predicted a vigilant strategy to be more effective in CSII therapy, because this strategy has been successful in situations that are influenceable. Therefore, patients with a vigilant coping strategy try to get along with a threatening situation (e.g., diabetes). Moreover, it is known that especially in diabetes patients, self-initiated activity toward glycaemic improvement is needed for positive outcomes (Pickup \& Keen, 2002). In line with this hypothesis, Graue et al. (2004) showed that coping style is associated with glycaemic control in patients with type 1 diabetes. If this relation was established, it would be important for psychological strategies in diabetes education. Through proper diabetes education, patients should be encouraged to turn toward and actively work on problems associated with diabetes mellitus. In general, we expected people using a vigilant coping strategy to collect more information about the disease and, thus, cope more effectively with CSII therapy. This can be expected to result in better glycaemic control.

A second factor, locus of control, focuses on individuals' generalized beliefs about the sources of reinforcement of behavior and may be related to psychological or metabolic outcomes in CSII. Internal locus of control indicates that, in general, individuals believe that they have control over their life and direct environment. In contrast, external locus of control means that important life events are considered to be dependent on external sources, such as other people (powerful others) or luck and coincidence (chance; Hexel, 2003; Steptoe \& Wardle, 2001). Thus, patients with an internal control orientation are thought to feel more responsible for their treatment, make necessary behavioral changes, and-as a consequence-may achieve better glucose control. External control orientation can be expected to work in the opposite way: Patients, believing the disease is beyond their own control, can be regarded as feeling less responsible, fail to take action, and, hence, they should have poor glucose control. Patients with an internal control orientation are consequently supposed to be more likely to apply pump therapy (Pickup \& Keen, 2002) because of their belief that they can influence their etiopathology. However, to date, studies have been inconsistent on the effects of control beliefs on diabetes in general (Chlebowy \& Garvin, 2006; Diem et al., 2004; Peyrot \& Rubin, 1994; Stenström, Wikby, Andersson, \& Ryden, 1998). Establishing this relation would be important because working on the control beliefs of the patient may enable the health-care professional to influence patients' ability to handle the disease. 
Last, a third construct that was assumed to affect outcome variables was perceived self-efficacy. Luszczynska and Schwarzer (2005) described perceived self-efficacy as "the belief in one's competence to tackle difficult or novel tasks and to cope with adversity in specific demanding situations" (p. 635). Recent studies have provided initial support for the assumption that a higher perception of self-efficacy in health behavior is related to better acquaintance with the insulin pump, resulting in better outcome variables (Ikeda, Aoki, Saito, Muramatsu, \& Suzuki, 2003), as well as with metabolic control in general (Johnston-Brooks et al., 2002; Nakahara et al., 2006). As with locus of control, for patients' education, working together with the therapist on a higher selfefficacy would encourage the patients to actively participate in the therapy process. A higher perception of self-efficacy in health behavior was thought to lead to greater ease in handling the insulin pump, resulting in better glycaemic control.

For outcome, we used a battery of psychological and physiological indicators. The psychological outcomes of treatment satisfaction, depressive symptoms, and quality of life were relevant to therapy success in diabetes in general (Bott, Ebrahim, Hirschberger, \& Skovlund, 2003; Lustman, Anderson, Freedland, de Groot, \& Carney, 2000; McMahon et al., 2005). In a successful therapy, treatment satisfaction and quality of life were expected to be higher, whereas depressive symptoms were expected to be lower. We used glycated haemoglobin $\left(\mathrm{HbA}_{1 \mathrm{c}}\right)$ as a metabolic outcome and expected it to decrease under successful insulin therapy.

In summary, the purpose of our study was to explore the influence of specific psychological factors (i.e., coping style, locus of control, self-efficacy) on major psychological outcome variables (i.e., treatment satisfaction, depressive symptoms, quality of life) and on glycaemic control in a growing but psychologically and largely underresearched subgroup of type 1 diabetes patients. Using multiple linear regression analyses, we included coping style, locus of control, and self-efficacy as statistical predictors for therapy success. Conceptually, we expected treatment satisfaction and quality of life to be higher and depressive symptoms to be lower in a successful therapy. To examine the relations among psychological factors as well as metabolic and psychological outcome variables, we tested the following hypotheses:

Hypothesis $1\left(H_{1}\right)$ : Patients with a more vigilant coping strategy should have better outcome (i.e., better glycaemic control, better quality of life, less depressive symptoms, higher treatment satisfaction).

$\mathrm{H}_{2}$ : Higher internal control orientation should be related to better outcomes, whereas higher external control orientations should be related to worse outcomes.

$H_{3}$ : Higher perception of self-efficacy in health behavior should be related to better outcome. 


\section{Method}

\section{Participants}

For possible inclusion, we screened all patients with type 1 diabetes (according to the World Health Organization criteria) who had started CSII through June 2003 at a major German diabetes center. To obtain informed consent, we contacted patients through postal mail or in person when they had an appointment at the department. In our analyses, we included the 51 patients who agreed and had complete data records. Before being introduced to CSII therapy, all patients had been on conventional intensified insulin therapy (ICT), which included four to eight injections per day.

Participants were 30 women $(58.8 \%)$ and 21 men (41.2\%). The mean age of the participants was 36.5 years $(S D=12.3$ years, range $=14-36$ years). Patients had between 4 and 18 years of education, with a mean of 11.2 years $(S D=3.3$ years). The duration of education was unknown for 4 participants. The mean duration of diabetes was 19 years $(S D=10$ years, range $=4-51$ years). At the onset of CSII, patients had been on ICT for 14.4 years ( $S D=$ 10.2 years, range $=1-49$ years) and a median of 3 years (interquartile range $=$ $2-4.5)$ on CSII. The mean BMI of participants was $24.7 \mathrm{~kg} / \mathrm{m}^{2}\left(S D=3.0 \mathrm{~kg} / \mathrm{m}^{2}\right.$, range $\left.=19-36 \mathrm{~kg} / \mathrm{m}^{2}\right)$.

\section{Instruments}

Psychological outcome. The questionnaire contained a German version of the Diabetes Treatment Satisfaction Questionnaire (Bradley, 1994). Patients rated satisfaction with their treatment by responding to items (e.g., "How satisfied are you with your current insulin therapy?") on a 7-point Likert-type scale ranging from 0 (very satisfied) to 6 (very unsatisfied).

Quality of life. We investigated quality of life using the state of health and wellbeing subscale of the VITA questionnaire (Deck, Kohlmann, \& Jordan, 2002), a short German questionnaire on health-related quality of life that was proven to be sensitive to diabetes-related issues (Kliegel, Mahnel, Martin, \& Jaursch-Hancke, 2002). The questionnaire contained items such as "My body is robust" and "I experience my body as capable." Participants rated each item on a 4-point Likerttype scale ranging from 0 (strongly agree) to 3 (strongly disagree).

Depressive symptoms. We assessed depressive symptoms by using the German version of the Self-Rating Depression Scale (Zung, 1965). In the present study, patients rated items (e.g., "I feel sad, depressed, and melancholic") on a 4-point Likert-type scale ranging from 0 (never) to 3 (most of the time).

Glycaemic outcome. We assessed $\mathrm{HbA}_{\mathrm{Ic}}$ because it is a reliable indicator of average serum glucose level over the preceding 2-3 months (Berger, 2000). A high $\mathrm{HbA}_{1 \mathrm{c}}$ 
level represented poorer metabolic control (American Diabetes Association, 1999). Furthermore, it is known to predict risks for diabetic complications in patients with types 1 and 2 diabetes (Diabetes Control and Complications Trial Research Group, 1993). We assessed $\mathrm{HbA}_{1 \mathrm{c}}$ using high pressure liquid chromatography (HPLC).

Psychological factors. Because psychological factors were assumed to be related to the outcome indicators, we assessed the MCI-P (Mainz Coping InventoryPhysical) subscale of the Mainz Coping Inventory (MCI; Krohne \& Egloff, 1999) in which patients decided on possible reactions to situations that represent physical threat (e.g., "Imagine that you are sitting in an airplane. The flight has been turbulent for quite a while now, and the no smoking and fasten seat belts signs have lit up"). Two general coping styles were assessed: vigilance, which is orienting toward stressful aspects of an aversive situation (e.g., "I pay attention to the sound of the engine") and cognitive avoidance, which is averting attention away from threatening information (e.g., "I read a newspaper or a book"; Schmuckle, Egloff, \& Krohne, 2000). Participants could agree or disagree with the behavior. In our study, a high score indicated a vigilant strategy. Scores ranged from 0 (highly cognitive avoidant) to 5 (highly vigilant).

We also included the German Questionnaire for Competence and Control Orientation (Krampen, 1991). This questionnaire measures locus of control in internal and external (subscales A [powerful others] and B [chance]) occurrence. A sample item for internal locus of control is "I can influence the good aspects in my life." A sample item for external locus of control regarding powerful others is "In general, other people take care of my life." A sample item for external locus of control regarding chance is "Most of the good things in my life are determined by accidental incidents." Participants rated items on a 5-point Likert-type scale ranging from 0 (strongly agree) to 4 (strongly disagree).

Last, we measured diabetes-specific self-efficacy by applying a questionnaire that Bott and colleagues developed (Bott, 1996; Bott et al., 2003). This questionnaire describes self-perceived ability to handle the disease. Sample items are "I believe I have learned to live with diabetes" and "I know how to handle even difficult problems with diabetes." Participants rated items on a 6-point Likert-type scale ranging from 0 (strongly agree) to 5 (strongly disagree).

\section{Procedure}

Although, from an international perspective, CSII is a growing therapy option, it is still difficult to obtain large-scale samples (e.g., see Benhamou et al., 2007); thus, to have a sample size that allowed the use of multiple regression analyses, we methodologically applied a retrospective design sampling the entire population of CSII patients at a major German diabetes center. Because all participants of our study were patients of the same clinical diabetes center and had initiated CSII therapy at this institution, clinical records were available for every participant. We asked participants to complete the standardized questionnaire as previously 
described. All patients were on CSII therapy when we administered the questionnaires. We told participants that the answers should refer to their current situation with insulin pump therapy. The participants completed the questionnaire during their visit to the diabetes center or after it arrived by postal mail.

\section{Statistical Analyses}

Using the Kolmogorov-Smirnov test, we tested the data for normal distribution. We tested correlations between medical and psychological data by applying bivariate Pearson's correlation coefficients. To test the hypothesis that psychological constructs may predict $\mathrm{HbA}_{1 \mathrm{c}}$ levels under CSII and psychological outcomes, we computed a series of ordinary least-squares multiple linear regression equations. Because of the number of participants, we entered five predictors into the models; most researchers recommend 10 subjects per predictor (Tabachnick \& Fidell, 1989). The current literature did not suggest a hierarchical order for the predictors we included in our study; thus, we simultaneously entered all factors in the equation. In addition, we determined explained variance by using $R^{2}$. The $p$ values were two-tailed, and values of $p<.05$ were considered significant. We performed all statistical analyses using SPSS (version 11.5) for Microsoft Windows.

\section{Results}

\section{Glycaemic Control With CSII}

Using data from the patient records, we first verified whether metabolic outcome had improved with the therapy changeover. We compared $\mathrm{HbA}_{\mathrm{Ic}}$ levels at ICT therapy and CSII. Also, we averaged the analyzed data across year before the therapy change and across year after the change from ICT to CSII. $\mathrm{HbA}_{1 \mathrm{c}}$ was significantly lower with CSII therapy $(7.1 \pm 0.9)$ than with ICT $(8.2 \pm 1.6)$, $p<.001$ (for more detailed analyses of this effect with a larger sample of this cohort, see Aberle et al., 2008).

\section{Correlations Between Psychological Factors and Outcome Variables}

In the second step, outcome variables and psychological factors were correlated (for descriptive data on the psychological parameters of the entire sample, see Table 1). As Table 2 shows, self-efficacy correlated negatively $(-.45)$ with depressive symptoms and positively with treatment satisfaction (.40) and quality of life (.60). Furthermore, a high external locus of control with attribution to chance was associated with high $\mathrm{HbA}_{1 \mathrm{c}}$ under CSII (.56) and more depressive symptoms (.42).

\section{Statistical Prediction of Outcome Variables}

The next step was to statistically predict medical and psychological outcomes using multiple linear regression analyses (see Table 3). Locus of control emerged 
TABLE 1. Descriptive Data on the Psychological Predictors and Outcomes $(N=51)$

\begin{tabular}{lcccc}
\hline \hline Variable & $M$ & $S D$ & Range & $\alpha$ \\
\hline Psychological predictor & & & & \\
$\quad$ Self-efficacy & 30.51 & 5.45 & $18.5-40$ & .78 \\
$\quad$ Coping style & 20.25 & 6.50 & $8.0-39$ & .86 \\
$\quad$ Locus of control & & & & \\
$\quad$ Internal & 15.08 & 3.03 & $8.0-22$ & .70 \\
$\quad$ External chance & 6.69 & 2.64 & $1.0-13$ & .75 \\
$\quad$ External others & 4.47 & 2.21 & $0.0-9.0$ & .73 \\
Outcomes & & & & \\
$\quad$ Depression symptoms & 14.47 & 7.46 & $2.0-36$ & .73 \\
$\quad$ Treatment satisfaction & 21.36 & 3.89 & $9.0-28$ & .86 \\
$\quad$ Quality of life & 32.79 & 8.11 & $17.5-47$ & .83 \\
\hline
\end{tabular}

Note. Data given as $M= \pm 1 S D$

as predictor of $\mathrm{HbA}_{\mathrm{Ic}}$ level under CSII. A high internal locus of control was related to lower levels of glycosylated haemoglobin $(\beta=-.36)$, whereas a high external locus of control with attribution to chance was associated with higher levels of $\mathrm{HbA}_{1 \mathrm{c}}(\beta=.52)$. External locus of control with attribution to powerful others, self-efficacy, and coping style had no additional predictive power for the $\mathrm{HbA}_{\mathrm{Ic}}$ level under CSII. Overall, psychological predictors explained $47.9 \%$ of the variance in $\mathrm{HbA}_{1 \mathrm{c}}$.

Regarding depressive symptoms in CSII patients, self-efficacy was found to be the most important predictor $(\beta=-.46, p<.001)$, indicating that high selfefficacy was associated with less depressive symptoms. In sum, all predictors explained $28.5 \%$ of the variance in depressive symptoms. Again, self-efficacy emerged as an important predictor for treatment satisfaction $(\beta=.38, p<.05)$, but high internal locus of control was found to be equally relevant $(\beta=.32)$. In the present study, the predictors explained $30.5 \%$ of the variance in treatment satisfaction. Last, as Table 3 shows, self-efficacy was also crucial for the prediction of quality of life under CSII; self-efficacy was the only significant but strong predictor $(\beta=.64)$. With all predictor variables, $45.7 \%$ of the variance in quality of life under CSII could be explained.

\section{Discussion}

We aimed to examine whether individual differences in medical and psychological diabetes-related outcomes were related to individual differences in psychological factors. Because previous investigations focused mostly on glycaemic outcomes or analyzed only one specific psychological factor, we assessed 


\begin{tabular}{|c|c|c|c|c|c|c|c|c|c|}
\hline Variable & 1 & 2 & 3 & 4 & 5 & 6 & 7 & 8 & 9 \\
\hline \multicolumn{10}{|l|}{ Outcomes } \\
\hline 1. $\mathrm{HbA}_{1}$ & - & & & & & & & & \\
\hline 2. Depressive symptoms & $.376^{*}$ & - & & & & & & & \\
\hline 3. Treatment satisfaction & -.239 & $-.525^{*}$ & - & & & & & & \\
\hline 4. Quality of life & -.108 & $-.542^{* *}$ & $.417^{*}$ & - & & & & & \\
\hline \multicolumn{10}{|l|}{ Psychological predictor } \\
\hline 5. Self-efficacy & -.285 & $-.453^{* *}$ & $.397^{* *}$ & $.601^{* *}$ & - & & & & \\
\hline 6. Coping style & -.031 & .052 & -.128 & -.224 & .076 & - & & & \\
\hline \multicolumn{10}{|l|}{ Locus of control } \\
\hline 7. Internal & -.159 & -.121 & .241 & .071 & -.042 & $-.296^{*}$ & - & & \\
\hline 8. External chance & $.564^{* * *}$ & $.417^{* * *}$ & -.216 & -.064 & -.234 & -.091 & .011 & - & \\
\hline 9. External others & .193 & .118 & .001 & .103 & .086 & -.152 & .057 & $.310^{*}$ & - \\
\hline
\end{tabular}


TABLE 3. Linear Regressions Predicting Outcomes ( $\beta$ )

\begin{tabular}{lcccc}
\hline \hline Variable & $\mathrm{HbA}_{1 \mathrm{c}}$ & $\begin{array}{c}\text { Depressive } \\
\text { symptoms }\end{array}$ & $\begin{array}{c}\text { Treatment } \\
\text { satisfaction }\end{array}$ & Quality of life \\
\hline Self-efficacy & -.214 & $-.464^{* *}$ & $.383^{*}$ & $.640^{* *}$ \\
Coping style & -.164 & .095 & -.077 & -.125 \\
Locus of control & & & & $.319^{\dagger}$ \\
$\quad$ Internal & $-.358^{*}$ & -.088 & .116 & .104 \\
$\quad$ External chance & $.523^{* *}$ & .148 & -.11 & -.030 \\
$\quad$ External others & .049 & .125 & -.074 & $.357^{*}$ \\
$R^{2}$ & $.479^{* *}$ & $.285^{\dagger}$ & $.305^{*}$ & $.457^{*}$ \\
\hline
\end{tabular}

Note. $\mathrm{HbA}_{1 \mathrm{c}}=$ glycated hemoglobin. $\mathrm{HbA}_{\mathrm{lc}}$ level represents the average across the 1 st year on continuous subcutaneous insulin infusion.

${ }^{\dagger} p=.05 .{ }^{*} p<.05 .{ }^{* *} p<.01$

outcome parameters that comprised glycaemic control and core psychological outcome variables. Therefore, our study was the first to integrate the most established psychological constructs, which are known to be associated with health outcome in chronic diseases.

It could be observed that a highly significant decrease in $\mathrm{HbA}_{\mathrm{Ic}}$ was obtained after the onset of CSII therapy. This is in line with most recent studies on the effectiveness of CSII treatment with regard to $\mathrm{HbA}_{\text {Ic }}$ (Aberle et al., 2008; Pickup et al., 2002; Weissberg-Benchell et al., 2003). In addition, and more important, the present study demonstrated interrelations of metabolic and psychological variables under CSII. The results displayed a significant and substantial relation between the level of CSII-related metabolic outcome $\left(\mathrm{HbA}_{\mathrm{lc}}\right)$ and psychological construct locus of control. A strong effect on $\mathrm{HbA}_{1 \mathrm{c}}$ resulted from scoring high on external locus of control with attribution to chance. The data suggested that a high external locus of control with attribution to chance was associated with poorer glycaemic control, meaning that patients who held fate or luck responsible for the results of CSII therapy had worse glycaemic control. In contrast, patients who reported a higher level of internal locus of control (those who felt responsible for the success of CSII therapy), had a more favorable change in glycaemic outcome. The psychological predictors that were included could explain almost half of the variance in the medical outcome under CSII. This demonstrates the important role that psychological factors may play regarding core physiological outcomes in diabetic patients who use insulin pump therapy. To the best of our knowledge, ours is the first study that revealed the relevance of psychological factors on medical outcomes in continuous subcutaneous insulin infusion therapy.

Furthermore, quality of life outcome variables were correlated with psychological predictors. In the present study, self-efficacy predicted the occurrence of 
depressive symptoms, treatment satisfaction, and overall quality of life in CSII patients. Consequently, patients who perceived their own action as successful in influencing the therapy process seemed to be less likely to develop depressive symptoms and reported higher treatment satisfaction and quality of life. This finding was of particular clinical importance because a recent study reported that CSII patients may display an elevated level of depressive symptoms (Reichel et al., 2005). Treatment satisfaction also seemed to be affected by internal locus of control, indicating that patients who perceived themselves in control of influencing their therapy process were more satisfied with CSII therapy than were other patients. Because treatment satisfaction is known to be associated with patient compliance, health-care decisions, glycaemic control (Brod, Skovlund, \& Wittrup-Jensen, 2006), locus of control should be considered an important factor in the progress of the diabetes disease.

A general limitation in this kind of retrospective study is that because of the uncontrolled design, the results may arise from other reasons (e.g., better followup care). However, all patients were already treated in the same clinical diabetes center before changing to CSII, and therefore significant systematic changes in patient's care seemed unlikely. As previously argued, prospective studies on this topic are needed to clarify these issues. More specifically, further studies would have to use controlled, experimental designs and systematically extend not only the number of psychological but also physiological outcome parameters (e.g., hypoglycaemic episodes).

Also, the fact that the present study rests on correlative data should be noted. Thus, the interpretation of the data should be made with caution. Because of the correlative nature, causal relations between psychological aspects and treatment success cannot be firmly established, and prospective longitudinal and experimental studies would have to corroborate our results.

The results of our study have major implications for patients and health-care professionals providing care and psychosocial education to people with diabetes. The results emphasize the importance of specific psychological predictors for the evaluation of future studies on CSII as well as for educational programs in CSII. By assessing those psychological variables known to affect metabolic control, practitioners will be able to identify patients that are in a critical psychological mindset and effectively support them in an early stage of disease by specific education. Our study revealed that psychological care may be an essential part in a successful CSII treatment and that the use of psychological instruments is strongly advised in CSII education.

Overall, our study is one of the first evaluations of psychological treatment success indicators, in combination with a wide range of psychological factors, that may be related to those outcome parameters in a relatively large cohort of adult CSII patients (Aberle et al., 2008). Results indicate a substantial relation between metabolic control and psychological factors, as well as between psychological factors and psychological outcomes variables indicating different 
aspects of therapy success. Specifically, our study calls attention to psychological factors, such as self-efficacy and internal and external locus of control, as being of particular importance for medical and psychological outcomes. For the latter, self-efficacy appeared to play a central role. The results show that perceived selfefficacy was the strongest predictor for all psychological outcomes. Nevertheless, more research is needed in this direction to give a more solid base of evidence and find more possible predictors of metabolic and psychological outcomes.

\section{AUTHOR NOTES}

Ingo Aberle is a PhD student of psychology in the Department of Psychology at Technische Universität Dresden. His research interests are psychological effects of diabetes, prospective memory across the life span, and cognitive development. Urte Scholz is an assistant professor in the Department of Psychology at the University of Zurich. Her research interests are theories of health behavior, self-regulation, stress, and coping. Birgit Bach-Kliegel is co-head of the Department of the Metabolism Center at the Hirslanden Clinic. Her research interests are CSII therapy and metabolic changes associated with diabetes. Christine Fischer is an educational psychologist at the School Counseling Center of Schwäebisch Hall. Her research interests are models of education, cognitive development, and dyscalculia. Martin Gorny is a senior diabetes health professional in the Department of Internal Medicine at the City Hospital Darmstadt. His research interests are diabetes education, nutrition management in diabetic patients, and psychological effects of diabetes. Karin Langer is a senior physician in the Department of Internal Medicine at the City Hospital Darmstadt. Her current research interests are CSII therapy, psychological effects of diabetes, and health management. Matthias Kliegel is the chair of developmental psychology in the Department of Psychology at Technische Universität Dresden. His research interests are cognitive development across the life span, developmental neuropsychology, and health behavior across the life span.

\section{REFERENCES}

Aberle, I., Zimprich, D., Bach-Kliegel, B., Fischer, C., Gorny, M., Kliegel A., et al. (2008). Continuous subcutaneous insulin infusion leads to immediate, stable, and longterm changes in metabolic control. Diabetes, Obesity \& Metabolism, 10, 329-335.

Adili, F., Larijani, B., \& Haghighatpanah, M. (2006). Diabetic patients: Psychological aspects. Annals of the New York Academy of Sciences, 1048, 329-349.

American Diabetes Association. (1999). Test of glycemia in diabetes. Diabetes Care, 22, S77-S79.

American Diabetes Association. (2005). Standards of medical care in diabetes (position statement). Diabetes Care, 28(Suppl. 1), S4-S36.

Arias, E., Anderson, R. N., Kung, H. C., Murphy, S. L., \& Kochanek, K. D. (2003). Deaths: Final data for 2001. National Vital Statistics Reports, 52, 1-115.

Benhamou, P. Y., Melki, V., Boizel, R., Perreal, F., Quesada, J. L., Bessieres-Lacombe, S., et al. (2007). One-year efficacy and safety of Web-based follow-up using cellular phone in type 1 diabetic patients under insulin pump therapy: The PumpNet study. Diabetes \& Metabolism, 33, 220-226.

Berger, M. (Ed.). (2000). Diabetes mellitus (2nd ed.). München, Germany: Urban \& Fischer.

Bott, U. (1996). Psychosoziale aspekte der krankheitsbewältigung und ihre beziehung zum therapieerfolg: Evaluation krankheitsspezifischer fragebogen bei typ-1 diabetikern 
[Psychosocial aspects of disease-related coping and the relation to therapy success]. Frankfurt am Main, Germany: Verlag.

Bott, U., Ebrahim, S., Hirschberger, S., \& Skovlund, S. E. (2003). Effect of the rapidacting insulin analogue insulin aspart on quality of life and treatment satisfaction in patients with type 1 diabetes. Diabetic Medicine, 20, 626-634.

Bradley, C. (1994). Diabetes treatment satisfaction questionaire (DTSQ). In C. Bradley (Ed.). The handbook of psychology and diabetes. A guide to psychological measurement in diabetes research and management (pp. 111-132). Chur, Switzerland: Harwood Academic.

Brod, M., Skovlund, S. E., \& Wittrup-Jensen, K. U. (2006). Measuring the impact of diabetes through patient report of treatment satisfaction, productivity and symptom experience. Quality of Life Research, 15, 481-191.

Centers for Disease Control and Prevention. (2004). National diabetes fact sheet: General information and national estimates on diabetes in the United States, 2003. Atlanta, GA: U.S. Department of Health and Human Services.

Chlebowy, D. O., \& Garvin, B. J. (2006). Social support, self-efficacy, and outcome expectations: Impact on self-care behaviors and glycemic control in Caucasian and African American adults with type 2 diabetes. Diabetes Educator, 32, 777-786.

Deck, R., Kohlmann, T., \& Jordan, M. (2002). Health-related quality of life in old age. Aging Male, 5, 87-97.

DeVries, J. H., Snoek, F. J., \& Heine, R. J. (2004). Persistent poor glycaemic control in adult type 1 diabetes. A closer look at the problem. Diabetic Medicine, 21, 1263-1268.

Diabetes Control and Complications Trial Research Group. (1993). The effect of intensive treatment of diabetes on the development and progression of long term complications in the diabetes control in insulin dependent diabetes mellitus. New England Journal of Medicine, 329, 977-986.

Diem, P., Frost, S. A., Augustiny, K., \& Radanov, B. P. (2004). Quality of life and coping behavior in type 1 diabetes mellitus: Relationship with metabolic control. Diabetes, Nutrition \& Metabolism, 17, 151-155.

Geiss, L. S., Herman, W. H., \& Smith, P. J. (1995). Mortality in non-insulin-dependent diabetes. In P. H. Bennett, E. J. Boyko, C. C. Cowie, M. I. Harris, M. P. Stern, \& G. E. Reiber (Eds.), Diabetes in America. (2nd ed., pp. 233-258). Bethesda, MD: National Institute of Health, National Institute of Diabetes and Digestive and Kidney Diseases.

Graue, M., Wentzel-Larsen, T., Bru, E., Hanestad, B. R., \& Søvik, O. (2004). The coping styles of adolescents with type 1 diabetes are associated with degree of metabolic control. Diabetes Care, 27, 1313-1317.

Hexel, M. (2003). Alexithymia and attachment style in relation to locus of control. Personality and Individual Differences, 35, 1261-1270.

Ikeda, K., Aoki, H., Saito, K., Muramatsu, Y., \& Suzuki, T. (2003). Associations of blood glucose control with self-efficacy and rated anxiety/depression in type II diabetes mellitus patients. Psychological Reports, 92, 540-544.

Johnston-Brooks, C. H., Lewis, M. A., \& Garg, S. (2002). Self-efficacy impacts self-care and $\mathrm{HbA}_{\mathrm{Ic}}$ in young adults with type I diabetes. Psychosomatic Medicine, 64, 43-51.

Kliegel, M., Mahnel, R., Martin, M., \& Jaursch-Hancke, C. (2002). Prädiktoren von verhaltensänderungen bei typ- 2 diabetikern [Predictors of behavioral change in type 2 diabetics]. Praxis Klinische Verhaltensmedizin und Rehabiliation, 60, 318-323.

Krampen, G. (1991). Questionnaire for competence and control orientation. Göttingen, Germany: Hogrefe.

Krohne, H. W. (1993). Vigilance and cognitive avoidance as concepts in coping research. In H. W. Krohne (Ed.), Attention and avoidance: Strategies in coping with aversiveness (pp. 19-50). Toronto, Canada: Hogrefe. 
Krohne, H. W., \& Egloff, B. (1999). The Mainz Coping Inventory (MCI) manual. Frankfurt, Germany: Swets Test Services.

Lustman, P. J., Anderson, R. J., Freedland, K. E., de Groot, M., \& Carney, R. M. (2000). Depression and poor glycemic control. A meta-analytic review of the literature. Diabetes Care, 23, $434-442$.

Luszczynska, A., \& Schwarzer, R. (2005). Multidimensional health locus of control: Comments on the construct and its measurement. Joumal of Health Psychology, 10, 633-642.

McEwen, L. N., Kim, C., Haan, M., Ghosh, D., Lantz, P. M., Mangione, C. M., et al. (2006). Diabetes reporting as a cause of death: Results from the Translating Research Into Action for Diabetes (TRIAD) study. Diabetes Care, 29, 247-253.

McMahon, S. K., Airey, F. L., Marangou, D. A., McElwee, K. J., Carne, C. L., Clarey, A. J., et al. (2005). Insulin pump therapy in children and adolescents: Improvements in key parameters of diabetes management including quality of life. Diabetic Medicine, 22, 92-96.

Nakahara, R., Yoshiuchi, K., Kumano, H., Hara, Y., Suematsu, H., \& Kuboki, T. (2006). Prospective study on influence of psychosocial factors on glycemic control in Japanese patients with type 2 diabetes. Psychosomatics, 47, 240-246.

Peyrot, M., \& Rubin, R. R. (1994). Structure and correlates of diabetes-specific locus of control. Diabetes Care, 17, 994-1001.

Pickup, J., Mattock, M., \& Kerry, S. (2002). Glycaemic control with continuous subcutaneous insulin injection therapy in type 1 diabetes. A meta-analysis of randomised controlled trials. British Medical Journal, 324, 1-6.

Pickup, J., \& Keen, H. (2002). Continuous subcutaneous insulin infusion at 25 years. Evidence base for the expanding use of insulin pump therapy in type 1 diabetes. Diabetes Care, 25, 593-598.

Reichel, A., Schwarz, J., Schulze, J., Licinio, J., Wong, M. L., \& Bornstein, S. R. (2005). Depression and anxiety symptoms in diabetic patients on continuous subcutaneous insulin infusion (CSII). Molecular Psychiatry, 10, 975-976.

Sacco, W. P., Wells, K. J., \& Vaughan, C. A. (2005). Depression in adults with type 2 diabetes: The role of adherence, body mass index, and self-efficacy. Health Psychology, 24, 630-634.

Schmuckle, S. C., Egloff, B., \& Krohne, H. W. (2000). Cross-situational consistent and variable coping modes. A latent-class analysis of the Mainz Coping Inventory. Diagnostica, 46, 199-207.

Stenström, U., Wikby, A., Andersson, P. O., \& Ryden, O. (1998). Relationship between locus of control beliefs and metabolic control in insulin-dependent diabetes mellitus. British Journal of Health Psychology, 3, 15-25.

Steptoe, A., \& Wardle, J. (2001). Locus of control and health behaviour revisited: A multivariate analysis of young adults from 18 countries. British Journal of Psychology, $92,659-672$.

Tabachnick, B., \& Fidell, L. (1989). Using multivariate statistics (2nd ed.). New York: Harper \& Row.

Talbot, F., \& Nouwen, A. (2000). A review of the relationship between depression and diabetes in adults: Is there a link? Diabetes Care, 23, 1556-1562.

Weissberg-Benchell, J., Antisdel-Lomaglio, J., \& Seshadri, R. (2003). Insulin pump therapy: A meta-analysis. Diabetes Care, 26, 1079-1087.

Zung, W. W. (1965). A self-rating depression scale. Archives of General Psychiatry, 12, $63-70$. 